\title{
A study on efficiency and effectiveness of suggestion system: A case study of oil products distribution
}

\author{
Samaneh Bahraminasab $^{\mathbf{a}^{*}}$, Fereydoon Azma ${ }^{\mathrm{b}}$ and Seyed Masoud Fakhri Tabtabaei ${ }^{\mathrm{c}}$
}

${ }^{a}$ M.Sc. Student, Department of Management, Aliabad Katoul Branch, Islamic Azad University, Aliabad Katoul, Iran

${ }^{b}$ Assist. Prof. and Faculty member, Department of Management, Aliabad Katoul Branch, Islamic Azad University, Aliabad Katoul, Iran ${ }^{c}$ Industrial Advisor and Employee National Iranian Oil Products Distribution, Tehran, Iran

\section{CHRON I C L E ABS T R A T}

Article history:

Received October 29, 2012

Received in revised format

15 December 2012

Accepted 17 December 2012

Available online

December 192012

Keywords:

Recommendation system

Efficiency

Effectiveness

Performance measurement

\begin{abstract}
One of the most important tools for improving the relative efficiencies of any organization is to establish suggestion system. Having a reliable system, which could reflect all employees' comments and concerns, helps managers take necessary actions to remove any possible obstacle in the system. In this paper, we measure efficiency and effectiveness of suggestion system in the National Iranian Oil Products Distribution. We also provide practical suggestions for improvement and necessary actions required to review the system. The proposed study of this paper uses a sample of 297 people from 1294 employees who work in different position for some of the regional offices of this firm in north part of Iran. The study has used two separate questionnaires, where the first one consists of 40 questions in Likert scale trying to measure the efficiency and effectiveness of the suggestion system. In addition, we use another questionnaire to rank important factors detected in the first stage. The results of questionnaires have been analyzed using different statistical tests.
\end{abstract}

\section{Introduction}

During the past few years, suggestion systems have received increasing attentions from researcers. Suggestions systems definitly can increase management capabilities on learning through feedback received and improving the entire system. A good suggestion system can disclose any existing shortcomings in the system and helps management team detect better solutions to overcome troubles. Despite the advantages, many manegers try not to use such systems for various reasons such as fear in management resistence, weakness in suggestions system, etc. However, there are many evidences, which indicate that management teams normally attempt to underestand their shortcoming through suggestion systems (Milner et al. 1995; Recht \& Wilderom, 1998; Heresy \& Blanchard, 2001; Anderson, 2004).

*Corresponding author. Tel: +989125320822

E-mail addresses: sbn_s1363@yahoo.com (S. Bahraminasab) 
Nouri and Ahanchi (2012) investigated the barriers of having recommendation systems in education system and focused on management team's shortcomings. They reported that lack of accepting risk among management team is number one barrier in having suggestion system followed by existing conflict between management style and suggestions system and lack of management's belief to suggestions system, weakness in education for suggestions system and fear in management disruption because of having suggestions system. The other barriers coming in the last priority in terms of their relative importance include lack of management's support to suggestions system and weakness in management position because of accepting suggestions system.

Pirayesh et al. (2012) presented a study to study the effect of information technology, hiring high quality skilled management team, using high quality standards and increasing employees' awareness on managing internal control. The survey implemented a questionnaire based on Likert scale and distributes among the people who work in either administration or financial sectors of governmental agencies in province of Zanjan, Iran. Their results showed that the implementation of information technology positively influences management team to control their system, more effectively, using more skilled and specialized managers positively influences management internal control, an organization with suitable standard positively influences management internal control and increasing employees' awareness positively influences management internal control.

Jun et al. (2006) performed an empirical investigation on the transferability of total quality management (TQM) practices to offshore manufacturing enterprises by validating relationships among top management commitment, human resource (HR)-focused TQM practices, employee satisfaction, and loyalty. The research objective was to isolate critical TQM practices, which would enhance employee satisfaction and loyalty among maquiladora workers. The results indicated that employee empowerment, teamwork, and employee compensation had an important and positive impact on employee satisfaction. Gao et al. (2011) investigated the role of leader trust and employee voice using the moderating impact of empowering leader behaviors.

Ahangari and Amirzadeh (2011) used a database of 360 corrective feedback moves where two EFL teachers provided to their learners at three levels of proficiency. Eight types of corrective feedback were detected and their distribution in relation to proficiency levels of learners was investigated. They reported that recast was the most frequently implemented kind of corrective feedback by the teachers at all three levels of proficiency. Atwater and Brett (2005) investigated the factors, which influence leaders' reactions to $360^{\circ}$ feedback and the relationship of feedback reactions to subsequent development activities and changes in leader behavior. Atwater and Brett (2005) stated that leaders with low ratings and the people who agreed with others about their ratings were less motivated than the people who received low ratings and over rated themselves. In addition, for leaders with high ratings, agreement between self and other did not impact their motivation.

Vakil Alroaia and Najafi (2012) investigated a $360^{\circ}$ feedback approach for performance measurement of all employees who worked for municipality of the city of Tabas located in east part of Iran. The proposed model of this paper also used hierarchical method to cluster various attributes based on different characteristics and implementd AHP to find out the relative importance of all items. The survey implemented five personal characteristics including cognitive, technical, personal and human skills and for each major item, the proposed model considers various sub-criteria. They reported that technical and cognitive skills were the most important personal characteristics followed by human and personal characteristics. The results of this survey also indicated that responsibility and quality of work are the most important employee characteristics.

Wood et al. (2004) examined the feasibility of a 360-degree evaluation to measure radiology resident competence in professionalism and communication skills. They implemented an evaluation form with 10 Likert-type items related to professionalism and communication skills was filled by a resident, 
supervising radiologist and patient after resident-patient interactions associated with breast biopsy procedures. They were also assessed by faculty, using an end-of-rotation global rating form. They studied 56 completed 360-degree data sets and seven rotational evaluations for seven residents. The results of this pilot study suggested that self, faculty, and patient evaluations of resident performance constituted a reliable evaluation of resident competence. However, they reported that more investigation were necessary to determine whether the 360-degree assessment could be incorporated into residency programs and how frequently the assessment could be performed.

The purpose of this study is to learn more about the barriers on having suggestion system in educational environment. The organization of this paper first present details of survey in section 2, section 3 presents the ranking system and concluding remarks are given in the last to summarize the contribution of the paper.

\section{The proposed study}

The proposed study of this paper uses a standard questionnaire and plan to distribute it among a randomly selected population from 1294 people who work for educational services in province of Golestan, Iran. The sample size is calculated as follows,

$$
n=\frac{N \times z_{\alpha / 2}^{2} \times p \times q}{\varepsilon^{2} \times(N-1)+z_{\alpha / 2}^{2} \times p \times q},
$$

where $N$ is the population size, $p=1-q$ represents the yes/no categories, $z_{\alpha / 2}$ is CDF of normal distribution and finally $\varepsilon=0.07$ is the error term. Since we have $p=0.5, z_{\alpha / 2}=1.96$ and $N=1294$, the number of sample size is calculated as $n=297$. In order to verify whether the data are normally distributed or not we use Kolmogorev-smirnov test (Peacock, 1983) where the null hypothesis is that data are normally distributed and Table 1 summarizes the results.

\section{Table 1}

The summary of Kolmogorev-smirnov test (KS) for data

\begin{tabular}{cll}
\hline Degree of freedom & KS & P-Value \\
\hline 264 & 0.133 & 0.098
\end{tabular}

As we can observe from the results of Table 1, P-value is well more than 0.05 and we cannot reject the null hypothesis and the distribution is normal. Next, we present details of the hypotheses along with the results of our statistical tests.

\section{The results}

In this section, we present details of our survey on testing various hypotheses of this survey.

\subsection{Management effectiveness perspective}

The first hypothesis is associated with management perspectives on suggestion systems.

$\mathrm{H}_{0}$ : The existing suggestion system is neither efficient nor effective in management's perspective.

$\mathrm{H}_{1}$ : The existing suggestion system is both efficient and effective in management's perspective.

In terms of effectiveness, the questionnaire consists of 13 questions in two groups of measuring the effectiveness of human resources and management team. 


\subsubsection{Measuring the effectiveness of human resources}

In our survey for measuring the effectiveness of human resources, there were 265 observations with mean of 3.5132. Table 2 demonstrates the results of our survey,

Table 2

Details of statistical observation on measuring the effectiveness of human resources

\begin{tabular}{lllllll}
\hline Factor & $\mathrm{N}$ & Mean & df & $\mathrm{t}$ & t-critical & Sig. \\
\hline Human resource effectiveness & 265 & 3.5132 & 264 & 18.846 & 1.96 & 0.000 \\
\hline
\end{tabular}

As we can observe from the results of Table 2, t-student is calculated as 18.846, which is well greater than 1.96 and we can reject the null hypothesis leading us to conclude that the existing suggestion system is both efficient and effective in management's perspective.

\subsubsection{Measuring the effectiveness of organization}

In our survey for measuring the effectiveness of organization, there were 265 observations with mean of 3.0189. Table 3 demonstrates the results of our survey,

\section{Table 3}

Details of statistical observations on measuring the effectiveness of organization

\begin{tabular}{lllllll}
\hline Factor & $\mathrm{N}$ & Mean & $\mathrm{df}$ & $\mathrm{t}$ & $\mathrm{t}$-critical & Sig. \\
\hline Organization effectiveness & 265 & 3.2528 & 264 & 12.348 & 1.96 & 0.000 \\
\hline
\end{tabular}

As we can observe from the results of Table 3, t-student is calculated as 12.348 , which is well greater than 1.96 and we can reject the null hypothesis leading us to conclude that the existing suggestion system is both efficient and effective in management's perspective.

\subsection{Recommendation efficiency}

This part of the survey includes measuring the impact of efficiency in terms of organization, management and human resources.

\subsubsection{Organizational efficiency}

In terms of measuring the efficiency of organization, we have had 265 observations with mean of 3.0189. Table 4 shows details of our survey,

\section{Table 4}

Details of statistical observations on measuring the efficiency of management

\begin{tabular}{lllllll}
\hline Factor & $\mathrm{N}$ & Mean & $\mathrm{df}$ & $\mathrm{T}$ & t-critical & Sig. \\
\hline Management efficiency & 265 & 3.0189 & 264 & 7.591 & 1.96 & 0.000 \\
\hline
\end{tabular}

As we can observe from the results of Table 4, t-student is calculated as 7.591, which is well greater than 1.96 and we can reject the null hypothesis leading us to conclude that the existing suggestion system has efficiently managed in terms of management's perspective.

\subsubsection{Efficiency organization}

In terms of measuring the efficiency of organization, we have had 265 observations with mean of 2.7660. Table 5 shows details of our survey, 
Table 5

Details of statistical observations on measuring the efficiency of organization

\begin{tabular}{lllllll}
\hline Factor & $\mathrm{N}$ & Mean & $\mathrm{df}$ & $\mathrm{T}$ & t-critical & Sig. \\
\hline Organization efficiency & 265 & 2.7660 & 264 & 3.830 & 1.96 & 0.000 \\
\hline
\end{tabular}

As we can observe from the results of Table 5, t-student is calculated as 3.830, which is well greater than 1.96 and we can reject the null hypothesis leading us to conclude that the existing suggestion system maintains efficient organization in management's point of view.

\subsubsection{Efficiency of human resources}

In terms of measuring the efficiency of human resources, we have had 265 observations with mean of 2.6566. Table 6 shows details of our survey,

Table 6

Details of statistical observations on measuring the efficiency of human resources

\begin{tabular}{lllllll}
\hline Factor & $\mathrm{N}$ & Mean & $\mathrm{Df}$ & $\mathrm{T}$ & $\mathrm{t}$-critical & Sig. \\
\hline Organization efficiency & 265 & 2.6566 & 264 & 2.131 & 1.96 & 0.000 \\
\hline
\end{tabular}

As we can observe from the results of Table 6, t-student is calculated as 2.131, which is well greater than 1.96 and we can reject the null hypothesis leading us to conclude that the existing suggestion system maintains efficient human resources in management's perspective.

\subsection{Strength of recommendation system}

Another aspect of this survey is to find the strength of recommendation system, which is measured in terms of management and organization.

\subsubsection{Strength of Management}

In terms of measuring the strength of management, we have measured 265 observations with mean of 2.6528. Table 7 shows details of our survey,

\section{Table 7}

Details of statistical observations on measuring the strength of management

\begin{tabular}{lllllll}
\hline Factor & $\mathrm{N}$ & Mean & Df & T & t-critical & Sig. \\
\hline Strength of management & 265 & 2.6528 & 264 & 2.460 & 1.96 & 0.000 \\
\hline
\end{tabular}

It is clear from the results of Table 7 that t-student is equal to 2.460, which is well greater than 1.96 and we can reject the null hypothesis leading us to conclude that the existing suggestion system maintains good management strength in terms of management's perspective.

\subsubsection{Strength of Organization}

In terms of measuring the strength of organization, we have considered 265 observations with mean of 2.3094. Table 8 shows details of our survey,

\section{Table 8}

Details of statistical observations on measuring the strength of management

\begin{tabular}{lllllll}
\hline Factor & $\mathrm{N}$ & Mean & $\mathrm{df}$ & $\mathrm{T}$ & t-critical & Sig. \\
\hline Strength of organization & 265 & 2.3094 & 264 & 3.134 & 1.96 & 0.000 \\
\hline
\end{tabular}


As we can observe from the results of Table 8, t-student is calculated as 3.134, which is well greater than 1.96 and we can reject the null hypothesis leading us to conclude that the existing suggestion system maintains good organizational strength in management's perspective.

\subsection{Analysis of suggestion system committee}

The other question of this survey investigates whether the current committee members are performing their jobs, efficiently and effectively. Table 9 shows details of our survey,

\section{Table 9}

Details of statistical observations on measuring the strength of management

\begin{tabular}{lllllll}
\hline Factor & $\mathrm{N}$ & Mean & df & T & t-critical & Sig. \\
\hline Suggestion committee & 265 & 2.6567 & 264 & 2.199 & 1.96 & 0.000 \\
\hline
\end{tabular}

As we can observe from the results of Table 9, t-student is calculated as 2.199, which is greater than 1.96 and we can reject the null hypothesis leading us to conclude that the existing committee has been efficient in management's perspective.

\subsection{Analyzing the effects of different factors}

The second part of our survey investigates whether the effects of different factors are equal or not. In other words, we study the following hypothesis,

$\mathrm{H}_{0}$ : There are some differences on the effects of different factors on suggestion systems.

$\mathrm{H}_{1}$ : There is no difference on the effects of different factors on suggestion systems.

Table 10 shows details of our findings on this survey,

\section{Table 10}

The results of parametric test

\begin{tabular}{llllll}
\hline Attribute & Mean & Sum of Squares & df & F & Sig. \\
\hline Intercept & 54548.408 & 54548.408 & 1 & 45250 & 0.000 \\
Error & 1.206 & 318.258 & 264 & & \\
\hline
\end{tabular}

As we can observe from the results of Table 10, F-statistics is meaningful and we can conclude that there are some differences on the effects of various factors on suggestion system. Table 11 summarizes details of the ranking of different factors in suggestion system. As we can see, three factors including continuous and periodic reporting of system performance recommendations, creating a positive attitude towards the staff recommendations as well as a good working environment for all employees with respect are the most important components in our survey. In order to have a successful recommendation system, it is very important that people believe in suggestion system. In addition, expanding the suggestion system to contractors, clients and families as well as creating competition among employee to offer suggestions and emphasis on group proposals are among the other important factors in our survey. There is no doubt that offering tracking facilities, mechanized review could contribute the system, significantly, and having a full-time executive secretary, interested, active and efficient are among other factors, which could contribute the suggestion system, substantially. 
Table 11

The summary of ranking different factors

\begin{tabular}{|c|c|c|c|c|c|c|}
\hline \multirow[b]{2}{*}{ Question } & \multirow[b]{2}{*}{ Item } & \multirow[b]{2}{*}{ Mean } & \multicolumn{4}{|c|}{ 95\% Confidence interval } \\
\hline & & & Std. Error & Lower & Upper & Rank \\
\hline 16 & $\begin{array}{l}\text { Continuous and periodic reporting of system performance } \\
\text { recommendations }\end{array}$ & 3.498 & 0.031 & 3.437 & 3.56 & 1 \\
\hline 17 & Creating a positive attitude towards the staff recommendations & 3.498 & 0.031 & 3.437 & 3.56 & 1 \\
\hline 18 & Creating a good working environment for all employees with respect & 3.498 & 0.031 & 3.437 & 3.56 & 1 \\
\hline 22 & Believe in suggestion system & 3.498 & 0.031 & 3.438 & 3.559 & 2 \\
\hline 13 & Expanding the suggestion system to contractors, clients and families & 3.494 & 0.031 & 3.433 & 3.556 & 3 \\
\hline 14 & Creating competition among employee to offer suggestions & 3.494 & 0.031 & 3.433 & 3.556 & 3 \\
\hline 15 & Emphasis on group proposals & 3.494 & 0.031 & 3.433 & 3.556 & 3 \\
\hline 6 & Offer tracking facilities and mechanized review & 3.109 & 0.055 & 3.002 & 3.217 & 4 \\
\hline 9 & Put on a full-time executive secretary, interested, active and efficient & 3.053 & 0.043 & 2.968 & 3.137 & 5 \\
\hline 12 & Enhance the creativity and skills of staff & 2.996 & 0.062 & 2.875 & 3.117 & 6 \\
\hline 8 & Information on the procedures & 2.955 & 0.054 & 2.849 & 3.06 & 7 \\
\hline 19 & Linking up the system with staff's associated with recommendations & 3.004 & 0.004 & 2.996 & 3.011 & 8 \\
\hline 5 & Fair judgment of all suggestions & 2.849 & 0.077 & 2.698 & 3.001 & 9 \\
\hline 7 & On time implementation & 2.868 & 0.057 & 2.756 & 2.98 & 10 \\
\hline 4 & Existence of reward system for suggestions & 2.766 & 0.041 & 2.686 & 2.846 & 11 \\
\hline 1 & Regulations and guidelines for implementation & 2.611 & 0.038 & 2.537 & 2.686 & 12 \\
\hline 2 & Appropriate criteria for evaluating proposed suggestions & 2.506 & 0.046 & 2.414 & 2.597 & 13 \\
\hline 3 & A dynamic system of committee recommendations & 2.513 & 0.031 & 2.452 & 2.575 & 14 \\
\hline 20 & Linking suggestions system with managers and administrators & 2.509 & 0.031 & 2.448 & 2.571 & 15 \\
\hline 21 & $\begin{array}{l}\text { Linking the proposed system to employee performance appraisal } \\
\text { system }\end{array}$ & 2.509 & 0.031 & 2.448 & 2.571 & 15 \\
\hline 23 & Managers tend to do group work and participation & 2.506 & 0.031 & 2.444 & 2.567 & 16 \\
\hline 24 & Encouraging employee to offer suggestions by their managers & 2.506 & 0.031 & 2.444 & 2.567 & 16 \\
\hline 11 & Educating employees based on the recommendations & 2.502 & 0.031 & 2.44 & 2.563 & 17 \\
\hline 10 & $\begin{array}{l}\text { Knowledge, skills and experience of the committee members } \\
\text { recommendations }\end{array}$ & 2.049 & 0.064 & 1.922 & 2.176 & 18 \\
\hline
\end{tabular}

\section{Conclusion}

In this paper, we have presented an empirical study to measure the impact of various factors on having a successful suggestion system in one of the biggest oil industries in Middle East. Based on the results of the survey, continuous and periodic reporting of system performance recommendations, creating a positive attitude towards the staff recommendations as well as a good working environment for all employees with respect are the most important components in our survey. In order to have a successful recommendation system, it is very important that people believe in suggestion system. In addition, expanding the suggestion system to contractors, clients and families as well as creating competition among employee to offer suggestions and emphasis on group proposals are among the other important factors in our survey.

\section{Acknowledgment}

The authors would like to thank the officials of National Iranian Oil Products Distribution for kindly cooperating in accomplishment of this survey. We are also grateful for constructive comments made by anonymous referees on earlier version of this paper.

\section{References}

Ahangari, S., \& Amirzadeh, S. (2011). Exploring the Teachers' Use of Spoken Corrective Feedback in Teaching Iranian EFL Learners at Different Levels of Proficiency. Procedia - Social and Behavioral Sciences, 29, 1859-1868.

Anderson, C.R. (2004). Management: Skills, Function, and Organization Performance, $2^{\text {nd }}$ ed., Boston: Allyn and Ban Com. 
Gao, L., Janssen, O., \& Shi, K. (2011). Leader trust and employee voice: The moderating role of empowering leader behaviors. The Leadership Quarterly, 22(4), 787-798.

Heresy, P. \& Blanchard, K. (2001). Management of organization. Behavior: Utilizing Human Resource. New York, Prentice - Hall International Edition, Fifth Edition.

Imai, M.(2002). Kaizen: The Key to Japan's Competitive Success. Random House business division, New York.

Jun, M., Cai, S., \& Shin, H. (2006). TQM practice in maquiladora: Antecedents of employee satisfaction and loyalty. Journal of Operations Management, 24(6), 791-812.

Milner, E., Kinnell, M. \& Usherwood, B. (1995). Employee Suggestion Schemes: a management tool for the 1990s? Library Management, 16(3), 3-8.

Nouri, M., \& Ahanchi, M. (2012). Identifying the management barriers for establishing suggestions system: A case study of educational system. Management Science Letters, 2(7), 2281-2286.

Peacock, J.A. (1983). Two-dimensional goodness-of-fit testing in astronomy. Monthly Notices of the Royal Astronomical Society, 202, 615-627.

Pirayesh, R., Niazi, R., \& Ahmadkhani, A. (2012). Investigating the effective factors on management internal controls applying. Management Science Letters, 2(4), 1203-1208.

Recht, R., \& Wilderom, C. (1998). Kaizen and culture: on the transferability of Japanese suggestion systems. International Business Review, 7(1), 7-22.

Vakil Alroaia, Y., \& Najafi, Z. (2012). Performance measurement of employee using an integrated $360^{\circ}$ feedback system and AHP method: A case study of municipality. Management Science Letters, 2(5), 1655-1660.

Wood, J., Collins, J., Burnside, E.S., Albanese, M.A., Propeck, P.A., Kelcz, F., Spilde, J.M., \& Schmaltz, L.M. (2004). Patient, faculty, and self-assessment of radiology resident performance:: A 360-degree method of measuring professionalism and interpersonal/communication skills. Academic Radiology, 11(8), 931-939. 